\title{
Tıp Dili ve Türkçe Üzerine Öğretim Üyesi Görüşleri
}

Faculty Member Opinions on Medical Language \& The Turkish Language Hüseyin Fatih Sevinç

Ortopedi ve Travmatoloji Kliniği, Nevşehir Devlet Hastanesi, Nevşehir/Türkiye

\section{ÖzeT}

AMAÇ: Erciyes Üniversitesi Tıp Fakültesi öğretim üyelerinin Türkçe ve Tıp dilinin güncel sorunlarına bakış açısını belirlemeyi amaçladık

GEREÇ VE YÖNTEM: Erciyes Üniversitesi Tıp Fakültesindeki 252 öğretim üyesinin 131’i (\%51,9) katılmıştır. Anket, öğretim üyelerinin Türkçenin sorunlarıyla, bilim ve Tıp diliyle ilgili bakış açılarını araştırmak için hazırlanmış çoktan seçmeli toplam 31 sorudan oluşmaktadır.

BULGULAR: Katılımcıların 126’sı (\%96,2) dilimizde kirlenme olduğunu düşünmektedir. Araştırmaya katılan öğretim üyelerinin 101 'i (\%77,1) Türkiye'de tıp alanında kullanılan dille ilgili sorun olduğunu düşünmektedir.

SONUÇ: Dilimize ne kadar güvenirsek, dilimizi ne kadar çok işlersek ve öğretirsek dilimiz o kadar çok gelişir. Bize düşen görev, bize bırakılan binlerce yıllık bu mirası en iyi şekilde koruyarak ve geliştirerek gelecek nesillere aktarmaktır.

Anahtar Kelimeler: tıp dili, tıp eğitimi, bilim dili

\section{ABSTRACT}

OBJECTIVE: This survey is purposed all the academic persons' point of view about daily problems of Turkish language and Medical language at Erciyes University Medical Faculty.

MATERIALS AND METHODS: Fifty-one point nine percent of the two hundred fifty-two academic persons' of the Erciyes University Medical Faculty joined our survey. This survey, totally thirty-one questions of multiple choices, includes those academic persons' points of view about the problems of Turkish language, scientific and Medical language.

RESULTS: One hundred twenty-six (ninety-six point two percent) academic persons' that has joined our survey think that there has been damage in our language. One hundred one (seventy-seven point six percent) academic persons' think that there are problems in Medical language in Turkey.

CONCLUSION: The more we trust our language and we teach our language, the more it develops. The things that we will do for our language are not an extra duty. Millions of Turkish people, who have lived all the history and are living, have the working and right on the Turkish culture and language. Our duty is to transfer this inheritance that has been coming for thousands of the years to next generations by saving and developing it with the best qualities.

Keywords: medical language, medical education, science language

\section{Giriş}

Duygu ve düşünceyi aktaran bir araç olan dil, insan topluluklarını anlamsız yığınlar olmaktan çıkararak aralarında duygu, düşünce ve amaç birliği olan bir toplum yani bir millet haline getirir (1). Dil, ulusun ses bayrağıdır. Bir ulusun bağımsızığı ve sonsuza kadar yaşaması, dilinin varlığı ve bağımsızıı̆ı ile olasıdır (2).

Kültür çeşitli açılardan ele alındığında, sosyal miras ve gelenekler bütünü, yaşam biçimi, idealler, değerler ve davranışlar, çevreye uyum, geniş anlamda eğitim, sosyal etkileşimin ürünü, düşünceler sistemi, maddi öğelerin, davranışların, düşünce ve duyguların simgesel örgütlenmesi olarak görülmektedir. Dillerin anlam içerikleriyle parçası oldukları kültürlerin içerikleri arasında tam bir örtüşme ya da özdeşlik vardır. Dil, kültür içeriğinin aynası, onun simgelerle yansıtılması, dile getirilmesidir. Kültürel ve tarihi miras, ancak dil aracılığıyla yeni kuşaklara aktarılır. Dil, kültürel muhtevanın bir ansiklopedisi, hazinesi ya da sözlüğü gibidir (3). Dil, düşüncenin evidir. Siz hangi dili konuşuyor, hangi dili yazıyorsanız, o dille düşünmeye başlarsınız. Düşünmeye başladığınız dil sizi o kültürün içine taşır (4).

Yazışma Adresi/Address for Correspondence: Hüseyin Fatih Sevinç, MD, Ortopedi ve Travmatoloji Kliniği, Nevşehir Devlet Hastanesi, Nevşehir/Türkiye E-Posta/E-Mail: drhfatihsevinc@gmail.com || Tel: +90 5556876296

Received/Geliş Tarihi: 11 Eki 2019 || Accepted/Kabul Tarihi: 29 Kas 2019

Bu Eser Creative Commons Atıf-Gayriticari 4.0 Uluslararası Lisansı İle Lisanslanmıştır. This work is licensed under a Creative Commons

Attribution-NonCommercial 4.0 International License (CC BY-NC 4.0). 
1987- 2001 arasında yayımlanan Pediatrik Cerrahi Dergisi'nin 15 cildi (33 dergi) dil yönünden incelenerek yapılan bir çalışma, tüm dergiler için genelleme yapmak için yetersiz olmakla birlikte, Tıp dilinin büyük ölçüde kirli ve yozlaşmış olduğunu ortaya koymaktadır. Bu çalışmada değerlendirilen 302 yazı başlığındaki yabancı sözcük oranı \% 47, 69 yazıda metin içindeki yabancı sözcük oranı $\% 48$ olarak bulunmuştur, 269 yazının Türkçe anahtar sözcüklerinin \% 62'sinin ve 15 Türkçe özetin sözcüklerinin \% 28'inin İngilizce sözcükler olduğu belirlenmiştir (5).

Tıp bilimi insan sağlığı ve hastalıklarıyla uğraşmasından dolayı halk tarafından diğer bilimlere oranla daha yakından takip edilmektedir. Halkın ilgisinin fazla olması sebebiyle Tıp dilinde kullanılan kelimeler toplumda hızla yayılmakta ve kullanılmaktadır. Onun için tıp biliminin üyesi olan herkesin, öğretim üyesinden doktora ve tıp öğrencisine kadar, kullandığı kelimelere daha fazla dikkat etmelidir.

Yabancı kökenli sözcükler, bu dilleri bilmediğimiz için bize bir şey çağrıştırmamakta, belleklerimizde açık bir anlam görüntüsü yaratmamaktadır. Bu yüzden Türkçe sözcükleri öğrenmek çok daha kolay olmaktadır. Yabancı sözcüklerin kullanıldığı durumlarda, öğrenme sürecini de olumsuz yönde etkileyen iletişim güçlükleri ortaya çıkmaktadır. Bu durumun acısını en çok çekenler kuşkusuz, öğretimi ve öğrenimi oldukça güç olan dirgerlik (hekimlik) alanında, kendilerine hiçbir şey çağrıştırmayan, on binlerce yabancı sözcüğü salt ses kalıpları olarak bellemek için olağanüstü çabalar gösteren tıp öğrencileridir (6). Tıp dilinde Türkçe karşılığı olmasına rağmen kullanılan yabancı kelimeler ve yabancı dille yapılan tıp eğitimi zaten yeterince zor olan tıp biliminin öğrenilmesini daha da zorlaştırmaktadır. Bu şekilde yetişen öğrencilerin, kendi ana dilleriyle öğrenip, düşünüp, kendilerini ifade edemedikleri için, Türk tıp bilimine katkıları daha az olmaktadır. Tıp eğitiminin temelinde kabaca usta-çırak ilişkisinin olduğunu düşünürsek, Tıp dilinde kullanılan kelimeler konusunda en büyük sorumluluk öğretim üyelerine düşmektedir.

Bu çalışmada, Erciyes Üniversitesi Tıp Fakültesi (EÜTF) öğretim üyelerinin Türkçe ve Tıp dilinin sorunlarına bakış açılarının belirlenmesi amaçlandı.

\section{GEREÇ VE YÖNTEM}

Bu araştırma Erciyes Üniversitesi Tıp Fakültesi Etik Kurulunun 01/465 karar numaralı onayı ile gerçekleştirilen ve EÜTF bütün öğretim üyeleri üzerinde anket yöntemi ile yapılmış tanımlayıcı tipte bir çalışmadır. Anket formları akademik kurullarda, ders aralarında, çeşitli derslerin sonlarında öğretim üyelerine dağıtılmıştır. Öğretim üyelerine anket formları dağıtılırken anketin amacı anlatılmıştır, sonrasında öğretim üyeleri anket formlarını kendileri doldurmuşlardır. Yanıtların güvenirliğini artırmak amacıyla öğretim üyelerinden isim ve soyadı yazmamaları istenilmiştir.

Çalışmamıza Erciyes Üniversitesi Tıp Fakültesindeki 252 öğretim üyesinin 131'i $(\% 51,9)$ katılmıştır. Katılımcıların $\% 80,2$ 'si erkek, \%19,1'i bayandır. Anket, öğretim üyelerinin Türkçenin sorunlarıyla, bilim ve Tıp diliyle ilgili bakış açılarını araştırmak için hazırlanmış çoktan seçmeli toplam 31 sorudan oluşmaktadır.

Veriler, bilgisayarda SPSS 17.0 programıla değerlendirilmiştir.

\section{BULGULAR}

Araştırmaya katılan öğretim üyelerinin 78 'i $(\% 59,5)$ tıp fakültesindeki hazırlık sınıfını gerekli gördüğünü, 44'ü $(\% 33,6)$ gerekli görmediğini, 9'u $(\% 6,9)$ da fikrinin olmadığını belirtmiştir. Katılımcıların 126'sı $(\% 96,2)$ dilimizde kirlenme olduğunu, 5'i $(\% 3,1)$ kirlenme olmadığını düşünmektedir. Dilimizde kirlenme olduğunu düşünen öğretim üyelerine, kirlenmenin boyutu sorulduğunda \%81,7'si çok fazla ve fazla, \%18,3'ü orta olarak belirtmiştir. Öğretim üyelerine dilimizi kullanırken ne kadar özen gösterdikleri sorulduğunda 89'u $(\% 67,9)$ çok fazla ve fazla, 37'si $(\% 28,2)$ orta, 5'i $(\% 3,9)$ az ve yetersiz özen gösterdiklerini belirtmişlerdir. İlkokuldan üniversiteye kadar verilen Türkçe eğitimini nasıl değerlendirdikleri sorulduğunda 24'ü $(\% 18,3)$ çok iyi ve iyi, 48'i $(\% 36,6)$ orta, 59'u $(\% 45,1)$ yetersiz ve çok yetersiz olarak değerlendirdiği saptandı.

Türk Dil Kurumu'nun (TDK) sözcük ve terim türetme çalışmalarını takip edenlerin \%25'i TDK'yi sözcük ve terim türetme konusunda çok iyi ve iyi, \%45,8'i orta, \%29,2'si yetersiz ve çok yetersiz olarak değerlendirmişlerdir. Öğretim üyelerinin 54'ü $(\% 41,3)$ derslerde tıp terimlerinin Türkçe karşılıklarının kullanılmasına çok fazla ve fazla özen gösterirken, 62'si $(\% 47,3)$ orta, 13'ü $(\% 9,9)$ az ve yetersiz özen gösterdiklerini belirtmişlerdir.

Katılımcıların 77'si $(\% 58,8)$ Tıp dilinin birkaç dilden kelimelerle karışık bir şekilde olmasının eğitimi olumsuz 
yönde etkilediğini, 45'i $(\% 34,4)$ etkilemediğini, 9'u $(\% 6,9)$ da fikrinin olmadığını belirtmiştir. Tıp dilinin birkaç dilden kelimelerle karışık bir şekilde olmasının eğitimi olumsuz yönde etkilediğini düşünenlerin $\% 37,7$ 'si bu etkinin çok fazla ve fazla, \%57,1'i orta, \%5,2'si az olduğunu belirtmişlerdir.

Tablo 1. Araştırmaya katılan öğretim üyelerinin çeşitli anket sorularına vermiş oldukları cevapların dağılımı

\begin{tabular}{|c|c|c|c|c|c|c|}
\hline & \multicolumn{2}{|c|}{ Evet } & \multicolumn{2}{|c|}{ Hayır } & \multicolumn{2}{|c|}{ Fikri Yok } \\
\hline & $\mathrm{n}$ & $\%$ & $\mathrm{n}$ & $\%$ & $\mathrm{n}$ & $\%$ \\
\hline Sizce yabancı dil öğretimi ile yabancı dille eğitim karıştırılıyor mu? & 111 & 84,7 & 12 & 9,2 & 8 & 6,1 \\
\hline Yabancı dil öğretimi gerekli midir? & 128 & 97,7 & 3 & 2,3 & - & - \\
\hline Yabancı dille eğitim gerekli midir? & 22 & 16,8 & 103 & 78,6 & 6 & 4,6 \\
\hline $\begin{array}{l}\text { Gelişmiş ülkelerin gelişmekte olan ülkelere dilleriyle birlikte kültürlerini de ihraç } \\
\text { ettiklerine inanıyor musunuz? }\end{array}$ & 125 & 95,4 & 5 & 3,8 & 1 & 0,8 \\
\hline Psikolojik savaş unsuru olarak dilin kullanıldığını düşünüyor musunuz? & 105 & 80,2 & 14 & 10,7 & 12 & 9,2 \\
\hline İngilizcenin evrensel bir dil olduğunu düşünüyor musunuz? & 100 & 76,3 & 30 & 22,9 & 1 & 0,8 \\
\hline İngilizceyi bilim dili olma konusunda yeterli görüyor musunuz? & 79 & 60,3 & 33 & 25,2 & 19 & 14,5 \\
\hline Türkçeyi bilim dili olma konusunda yeterli görüyor musunuz? & 59 & 45,0 & 58 & 44,3 & 14 & 10,7 \\
\hline Tıp fakültesinde yabancı dille eğitim yapılmasını ister misiniz? & 15 & 11,5 & 109 & 83,2 & 7 & 5,3 \\
\hline Türkiye'deki bilim dilinin yabancı dillerin etkisi altında kaldığını düşünüyor musunuz? & 127 & 94,7 & 6 & 4,6 & 1 & 0,8 \\
\hline Türk Dil Kurumunun sözcük ve terim türetme çalışmalarını takip ediyor musunuz? & 48 & 36,6 & 74 & 56,5 & 9 & 6,9 \\
\hline
\end{tabular}

Tablo 2. Tıp dilinin birbirine karışmış, birkaç dilden oluşmasının nedenlerine yönelik düşüncelerin dağılımı*

\begin{tabular}{|c|c|c|}
\hline & $\mathrm{n}$ & (\%) \\
\hline Bir kere sözcükler yerleştikten sonra bunları değiştirmenin çok zor oluşu & 93 & 71,0 \\
\hline Tıbbın büyük bir hızla gelişmesi sonucu ortaya çıkan pek çok yeni terime zamanında karşılık bulunmaması & 94 & 71,8 \\
\hline Türkçe karşıllı̆ıı olan sözcükleri kullanma gereksinimi bilincinin zayıflığı & 71 & 54,2 \\
\hline Yabancı sözcük kullanma tutkusu & 50 & 38,2 \\
\hline Küreselleşen dünyanın doğal bir sonucu & 41 & 31,3 \\
\hline Türkçenin yeni terimlere karşılık bulabilecek kadar zengin bir dil olmaması & 17 & 13,0 \\
\hline
\end{tabular}

* Soruya bir öğretim üyesi birden fazla cevap verebilmiştir.

Tablo 3. Türkiye'de tıp alanında kullanılan dille ilgili sorunun nasıl çözülebileceğine yönelik önerilerin dağılımı* $(n=101)$

\begin{tabular}{|c|c|c|}
\hline & $\mathrm{n}$ & $(\%)$ \\
\hline Türkçe karşılı̆̆ı olan yabancı terimlerin kesinlikle Türkçe karşııkları kullanılmalı & 85 & 84,2 \\
\hline Bütün eğitimcilere ve öğrencilere anadil duyarlılı̆̆ı ve bilinci yerleştirilmeli & 74 & 73,3 \\
\hline Tıp eğitimi ve öğretimi anadilde yapılmalı & 59 & 58,4 \\
\hline YÖK'te kurullar kurulup, bu kurullar dünyadaki yeni gelişen terimleri yakından izleyip, bu terimlere karşılıklar bulmalı & 57 & 56,4 \\
\hline Türkçe karşıı̆̆ı olmayan yabancı terimlere Türkçe karşılık bulunması için yoğun çaba gösterilmeli & 59 & 58,4 \\
\hline
\end{tabular}

Türkiye'de tıp alanında kullanılan dille ilgili sorunun varlığı sorulduğunda öğretim üyelerinin 101'i $(\% 77,1)$ sorun var derken, 23'ü $(\% 17,6)$ sorunun olmadığını, 7'si $(\% 5,4)$ fikrinin olmadığını belirtmişlerdir.

\section{TARTIŞMA}

Dilimize giren her yabancı kelime, dilimizde bozulmaya, yabancılaşmaya zemin hazırlamakta ve toplumsal olarak bireyler arasında bağ ve yakınlığın azalmasına neden olmaktadır (7). Araştırmaya katılan öğretim üyelerinin büyük bir kısmının $(\% 84,7)$ ifade ettiği gibi Türkçenin her alanında kullanılan (bilim, konuşma, sanat gibi) yabancı kelimeler dilimizde sorun oluşturmaktadır ve bu sorun gün geçtikçe artmaktadır. Her dil belirli ölçülerde toplumsal, siyasal, ekonomik ve kültürel ilişkilere bağlı olarak diğer dillerden etkilenmekte ve onları etkilemektedir. Bu doğal bir 
süreçtir (7). Ancak dikkat edilmesi gereken doğal süreç gibi gösterilen dilimizdeki ve kültürümüzdeki kasıtlı ve ilerleyici yozlaşmadır. Bütün tarih boyunca insanlar birbiriyle iletişim içinde olmuştur. Günümüzde artan teknolojiyle birlikte toplumlararası iletişim en üst noktalara çıkmıştır. Toplumlararası iletişim artıkça diller arasında kelime alışverişi kaçınılmaz hale gelmektedir. Günümüzde Türkçenin durumu ise doğal bir süreç olmaktan çok uzakta olup, katılımcıların tamamına yakınının $(\% 96,2)$ belirttiği gibi, artık kirlenme boyutundadır. Yine benzer şekilde tıp fakültesi öğrencileriyle yapılan anket çalışmasında öğrencilerin \%90,2'si dilimizde kirlenmenin olduğunu düşünmektedir (8). Başka bir çalışmada Ulusal Çocuk Cerrahisi kongrelerinde yapılan sunumlarda kullanılan Türkçenin yozlaşma ve kirlenmesini gösteren somut örnekler belirlenmiştir (9). Bütün bunlar bize dilimiz konusunda daha hassas olmamı gerektiğini göstermektedir.

Eğer dünyanın başka bir yerinde teknoloji, bilim, sanat gibi herhangi bir alanda sizden daha gelişmiş bir toplum varsa bu yenilikleri, buluşları kısacası gelişmiş toplumların bilimini takip edebilmek için o milletin dilini öğrenmekten başka bir çaremiz yoktur. Bu ve bunun gibi birçok nedenden dolayı günümüz şartlarında yabancı dil öğrenmenin gerekliliğini tartışmak zaman kaybıdır ama araştırmaya katılan öğretim üyelerinin \%84,7'sinin ifade ettiği gibi yabancı dil öğrenimi ile yabancı dille eğitim karıştırılmaktadır. Bu iki kavram net bir şekilde birbirinden ayrılmalıdır. Yabancı dil öğrenmenin en iyi yolunun yabancı dille eğitimle olacağı düşüncesi yanlıştır. Hatta TDK eski başkanı Şükrü Haluk Akalın'ın dediği gibi “Türkçe bugün yabancı dillerin özellikle de İngilizcenin yoğun etkisine uğramışsa bunda esas sebep yabancı dille öğretimdir" (10). Yabancı dille eğitim yaparak gençlerimize ne iyi bir eğitim ne de iyi bir yabancı dil öğrenimi verilebilir. Daha da önemlisi yabancı dille eğitim, öğrencinin öğrenme isteğini, bilime ilgisini ve kendine güvenini yitirmesine; toplumsal düzeyde ise ulusuna, devletine, ana diline, kültürüne olan güvenini ve bağlılı̆ını yitirmesine yol açmaktadır (11). Araştırmaya katılan öğretim üyelerinin \%83,2'sinin Erciyes Üniversitesi Tıp Fakültesinde yabancı dille eğitim verilmesini istememeleri ve \%77,1'inin tıp eğitiminin yabancı dille olmasının öğrenmeyi olumsuz etkilediğini belirtmeleri yabancı dille eğitimin gereksiz olduğunu vurgulamaktadır.
Bir ulusu ayakta tutan o ulusun milli değerleri yani kültürüdür. Kültürün temelini ise o milletin dili oluşturur. Kısacası bir milleti yaşatan temel unsur o milletin dilidir. Günümüzde işgaller önce kültür ve dil aşılanması ile yapılmaktadır. Kültür emperyalizmi adı verilen bu yayılmacılığı amaç edinmiş ülkeler, yaşama biçimleri ve yeme içme modelleriyle, ulus bilinci gelişmemiş, toplumları kolaylıkla egemenlikleri altına almayı başarmakta, o ülkenin dilini ve kültürünü bozmak için iletişim araçlarını da arkalarına alarak her türlü bozulmaya destek olmaktadırlar (2). Öğretim üyelerinin \%80,2'sinin ifade ettiği gibi psikolojik savaş unsuru olarak dil kullanılmaktadır. Günümüzde psikolojik savaş unsuru olarak yazılı ve görsel basın, internet, sinema gibi birçok araç kullanılmaktadır. Economist dergisinin yaptığı araştırma sonucu toplam web sitelerinin \%78'i İngilizce olduğu ortaya çıkmıştır. Fakat güvenli sunuculara bağlı sitelerde bu pay çok daha yüksek ve güvenli sunuculara bağlı web sayfalarını \%91'i ingilizce olduğu belirtilmiştir (12). Dilleriyle birlikte öğretim üyelerinin tamamına yakınının $(\% 95,4)$ belirttiği gibi gelişmiş ülkeler, gelişmekte olan kültürlerini de ihraç etmektedirler.

Araştırmaya katılan öğretim üyelerinin $\% 94,7$ 'sinin ifade ettiği gibi bilim dilimiz yabancı dillerin etkisi altında kalmaktadır. Özellikle Tıp dili İngilizce, Latince, Fransızca, Almanca gibi kelimelerle karışık bir şekil almıştır. Öğretim üyelerin \%58,8'i Tıp dilinin bu yapısının eğitimi olumsuz etkilediğini düşünmektedir ve Tıp dilinin bu yapısının eğitimi olumsuz etkilediğini düşünenlerin \%94,8'inin bu olumsuz etkinin fazla ve orta olarak ifade etmesi tıp eğitiminde sorun olduğunu göstermektedir. Yabancı terim ve kavramların Türkçesinin öğrenilememesi ve günlük yaşamda kullanılmaması öğrencileri ezberciliğe yöneltir, yeni fikir üretmeyi ve bilimsel gelişmeyi kısıtlar (13). Araştırmaya katılan öğretim üyelerinin $\% 77,1^{1}$ inin belirttiği gibi Türkiye'de tıp alanında kullanılan dille ilgili sorun vardır. Bu sorunun çözülebilmesi için öncelikle Tıp dilinin birbirine karışmış, birkaç dilden oluşmasının nedenlerini ortaya koymamız gerekir. Bu nedenlerin başında tıbbın büyük bir hızla gelişmesi sonucu ortaya çıkan pek çok yeni terime zamanında karşılık bulunmaması, bir kere sözcükler yerleştikten sonra bunları değiştirmenin çok zor oluşu ve Türkçe karşılı̆̆ı olan sözcükleri kullanma bilincinin azlığı gelmektedir. Bizler ne Kaşgarlı Mahmut'un, ne Ali Şir Nevai'nin, ne Âşık Paşa'nın, ne Yunus Emre'nin, ne de Atatürk'ün Türkçemize yaptıkları katkıları yapabiliriz. Hatta 
yaptığımız işler onların yaptıklarıyla karşılaştırılamayacak kadar küçüktür. Ancak küçük çabaların büyük sonuçlar doğurabilme gücüne inanmalıyız. Türkçenin yaşadığı sorunlar her bilim dalındaki kullanılan dille ilgili sorunları birlikte getirmektedir. Ilk olarak bize düşen kendi bilim dilimizdeki sorunları ve bu sorunları oluşturan nedenleri ortaya koymaktır. Şu an bizim yapabileceğimiz çözüm önerileri sunmaktan ibarettir çünkü gerçek çözümün, ulusal düzeyde kurumların öncülüğünde, zaman içerisinde olacaktır. Türkiye'de tıp alanında kullanılan dille ilgili sorunların çözümünde öncelikle yapabileceğimiz Türkçe karşılığı olan yabancı terimlerin kesinlikle Türkçe karşılıkların kullanılmasıdır. Elbette bu, sorunu doğrudan çözmez ama Tıp dilindeki ilerleyici yabancılaşmanın önüne geçmiş oluruz. Tabiî ki bu konuda en büyük sorumluluk başta öğretim üyelerine ve geleceğin öğretim üyesi olacak olan öğrencilere düşmektedir. Bütün eğitimcilere ve öğrencilere ana dil duyarlılığı ve bilinci yerleştirerek, Türkçe karşılığı olan yabancı terimlerin Türkçe karşııklarının kullanılmasını sağlayabiliriz. Türkçe karşılılığı olmayan kelimelerin ise karşılıklarının bulunması için yoğun çaba göstermeliyiz. Bu çabanın bireysel olmaktan öte kurumsal olarak yapılması çok önemlidir. Bireysel olarak bulunan Türkçe karşılıkların ulusal düzeyde kabul görmeden kullanılması Tıp dilindeki karışıklığı artırabilir. Ulusal düzeyde Yükseköğretim Kurulu ya da TDK tarafından oluşturulan büyük çapta kurulların kurulması veya mevcut olan kurulların genişletilmesiyle kendi milli Tıp dili birliğimizi sağlam temeller üzerine kurabiliriz. Hatta her üniversitede oluşturulan küçük kurullar buldukları karşılıkları genel kurullarda sunarak daha fazla kişinin katılımıyla daha fazla ve hızlı Türkçe karşılıklar bulabiliriz. Tıp eğitiminin Türkçe olarak yapılması tıp alanında kullanılan dille ilgili sorunun çözümünde katkı sağlayabilir.

Ulu önderimiz Mustafa Kemal Atatürk "Milli his ile dil arasındaki bağ çok kuvvetlidir. Dilin milli ve zengin olması milli hissin gelişmesinde başlıca etkendir. Türk dili, dillerin en zenginlerindendir; yeter ki bu dil şuurla işlensin. Ülkesini, yüksek istiklalini korumasını bilen Türk milleti, dilini de yabancı dillerin boyunduruğundan kurtarmalıdır." diyerek Türk milletine, her konuda olduğu gibi, Türk dili konusunda da yol göstermiş, önderlik etmiştir. Unutmayalım ki dilimize ne kadar güvenirsek, dilimizi ne kadar çok işlersek ve öğretirsek dilimiz o kadar çok gelişir. Dilimiz konusunda yaptıklarımız ve yapacaklarımız bizim için ek bir görev değildir. Bu zengin Türk kültürü ve dili şu anda bize emanettir. Bize bırakılan binlerce yıllık bu mirası en iyi şekilde koruyarak, geliştirerek ve gelecek nesillere aktararak üzerimize düşen görevi yerine getirmeliyiz.

\section{Teşekkür}

Bu çalışmanın planlanması ve oluşturulmasında emeği çok fazla olan, 2013 yılında vefat eden, değerli hocam Prof. Dr. Mustafa Karacagil'e çok teşekkür ederim.

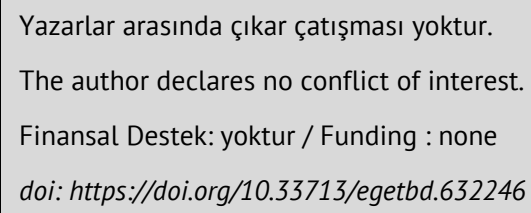

\section{KAYNAKLAR}

1. Argunşah M. Dil Yarası. 2. Baskı. İstanbul: Türk Ocağı Yayınları; 2006. Sf 33

2. Başçetinçelik A. Dil Toplumun Onurudur. Çukurova Üniv. Türkoloji Araştırma Merkezi. 2008 [19.11.08] http://turkoloji.cu.edu.tr/DIL\%20SORUNLARI/ayse_bascetincelik _dil_toplumun_onurudur.pdf

3. Tosun C. Dil Zenginliği, Yozlaşma ve Türkçe. Journal of Language and Linguistic Studies 2005; Vol. 1, No.2

4. Argunşah M. Dil Yarası. 2. Baskı. İstanbul: Türk Ocağı Yayınlarl; 2006. Sf 47

5. Sander S.Yazdığımız Dil. Pediatrik Cerrahi Dergisi 2003;17:611

6. Atmaca N S. Türk Tıp Dili Niçin Özleştirilmelidir? Güncel Gastroenteroloji 2014; 18/4: 390-400

7. Küçük S. Dil Kirliliğinin Türkçemize Yansımaları. Türk Dili Dergisi. 2007;669, 507

8. Sevinç H F, Karacagil M. Tıp Dili ve Türkçe Üzerine Öğrenci Görüşleri, Erciyes Med J. 2009; 31(3): 250-255

9. Sander S. Ulusal Çocuk Cerrahisi Kongrelerindeki Türkçe Özetler: Sorun yalnız yabancı sözcükler mi? Çocuk Cerrahisi Dergisi 31(2):35-42, 2017

10. Akalın Ş. Türkçeden Başka Bir Dille Eğitim?. Türk Dili Dergisi. 2002; 603,29

11. Köksal A. Yabancı Dille Eğitimden Caymak Zorundayız. Çukurova Üniv. Türkoloji Araştırma Merkezi.2008 [19.11.08] http://turkoloji.cu.edu.tr/DIL\%20SORUNLARI/08.php

12.Işık A. Milli Savunma ve Yabancı Dil, Güvenlik Stratejileri Dergisi 2008; 4(8)

13. Sav A. Yabancı Dil ile Yükseköğretim Üzerine, Bilim, Eğitim ve Düşünce Dergisi. 2003;3(1) 